\title{
Screening for cystic fibrosis: a four year regional experience
}

\author{
G ROBERTS, M STANFIELD, ${ }^{*}$ A BLACK,${ }^{*}$ AND A REDMOND* \\ Department of Clinical Biochemistry, Royal Victoria Hospital, Belfast and * Royal Belfast Hospital for Sick \\ Children
}

SUMMARY A four year regional screening programme to detect cystic fibrosis using measurement of immunoreactive trypsinogen is described. During this period 60 infants were diagnosed; 34 by screening, 12 born with meconium ileus, and 14 not identified by the screening assay but who presented with clinical symptoms at a later age, giving an incidence of cystic fibrosis in the region during this time of $1 / 1807$. Screening has resulted in earlier detection of cystic fibrosis in many infants, thus allowing treatment to be instituted at an early age, and genetic counselling offered to the parents. There were a number of false positives and false negatives with the immunoreactive trypsinogen screening assay. In addition, eight infants who were sweat tested at an early age had a sweat sodium concentration of $<70 \mathrm{mmol} / 1$, although they were subsequently shown to have cystic fibrosis. These results confirm other published data showing that sweat sodium results may be low in very young infants with cystic fibrosis. At the time of diagnosis seven $(20 \%)$ of the infants identified by screening were totally asymptomatic and several additional children had symptoms of such a type that the diagnosis of cystic fibrosis had not been considered at the time of screening. Despite the problems experienced it has been decided to continue screening.

It has been reported that immunoreactive trypsinogen concentrations were raised in blood in infants with cystic fibrosis. ${ }^{1}$ A number of subsequent trials have shown that immunoreactive trypsinogen could be estimated on dried blood spots as a screening assay for cystic fibrosis in the new born period. ${ }^{2} 3$ These reports showed encouraging results, and thus it was decided that it would be useful to assess the ability of this assay to detect cystic fibrosis in conjunction with the existing screening programme for phenylketonuria and congenital hypothyroidism in Northern Ireland.

\section{Methods}

Blood specimens, obtained by heel prick and collected on to filter paper cards, were taken between 5 and 8 days of age from all infants born in Northern Ireland. Before August 1983 these samples were used to screen for phenylketonuria and congenital hypothyroidism. Since August 1983 measurement of immunoreactive trypsinogen has been included as a screening test for cystic fibrosis. A second heel prick sample was obtained from all infants whose initial trypsinogen value was high, usually at 3-4 weeks of age. If the repeat trypsinogen concentration was also high the baby was seen by a paediatrician with experience in management of cystic fibrosis, and a full clinical examination and sweat test carried out; the child was usually 4-6 weeks old at this time.

Measurement of immunoreactive trypsinogen, on blood spot specimens, was carried out using the CIS Neonatal Trypsin Radioimmunoassay (CIS (UK) Ltd). The within assay coefficients of variation for the three concentrations of immunoreactive trypsinogen, 24,55 , and $108 \mu \mathrm{g} / \mathrm{l}$, were $8 \cdot 5 \%, 6 \cdot 1 \%$, and $5 \cdot 2 \%$, respectively. The between assay coefficients of variation at the same concentrations were $9.3 \%$, $8 \cdot 3 \%$, and $7 \cdot 7 \%$, respectively. From a precision profile for the assay the range for which the between assay coefficient of variation is $<10 \%$ has been shown to be $10-140 \mu \mathrm{g} / \mathrm{l}$. To establish a reference range for the assay immunoreactive trypsinogen measurements were carried out on 4000 infants born during June and July 1983. These results were not included in the four year period of assessment of the assay, and one infant born during June and July 
1983 was subsequently shown to have cystic fibrosis. A frequency distribution of immunoreactive trypsinogen results on these 4000 infants is shown in fig 1 . The value at the 95 th centile is $80 \mu \mathrm{g} / \mathrm{l}$ and at the 98th centile is $120 \mu \mathrm{g} / \mathrm{l}$.

During the first year of blood trypsinogen screening in Northern Ireland the 98th centile was used as the cut off level. Thus a second sample was requested on any infant whose initial screening result exceeded $120 \mu \mathrm{g} / \mathrm{l}$. If the trypsinogen value for the repeat sample was also greater than $120 \mu \mathrm{g} / \mathrm{l}$ the child was referred for a sweat test and a clinical examination. After one year of screening, using this cut off value, four false negatives had been identified, and in three of these the results were between the 95th and the 98th centile for the assay. For this reason, it was decided to alter the cut off value to the 95 th centile $(80 \mu \mathrm{g} / \mathrm{l})$, and this value has been used as the cut off since August 1984.

Sweat tests were carried out using the method of Gibson and Cooke. ${ }^{4}$ A sweat sodium concentration of greater than $70 \mathrm{mmol} / \mathrm{l}$ was considered to be suggestive of cystic fibrosis in the neonate. In infants with equivocal sweat sodium results- $-40-70 \mathrm{mmol} / \mathrm{l}$ - the sweat test was repeated. A diagnosis of cystic fibrosis was not made until three tests with sweat sodium concentrations $>70 \mathrm{mmol} / \mathrm{l}$ were obtained. Since 1985 the sweat chloride concentration has also been measured and a concentration of $>70 \mathrm{mmol} / 1$ considered to be commensurate with a diagnosis of cystic fibrosis. The sweat chloride is often greater than the sweat sodium concentration in cystic fibrosis, and the sum of the sweat sodium and sweat chloride concentrations greater than $140 \mathrm{mmol} / \mathrm{l}$.

\section{Results}

IMMUNOREACTIVE TRYPSINOGEN CONCENTRATIONS During the four year period 108424 infants were

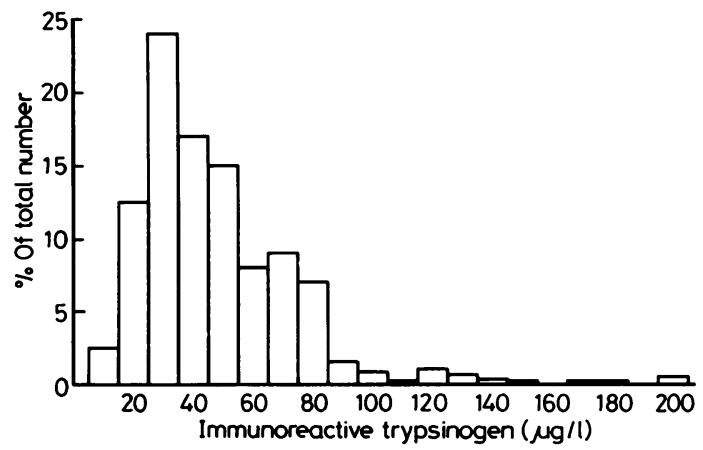

Fig 1 Frequency distribution of blood immunoreactive trypsinogen results in 4000 infants, taken consecutively. screened, and a second specimen was requested from $5120(5 \%)$ in whom the initial trypsinogen result was greater than the cut off level. A second raised trypsinogen concentration was measured in 136 of these repeats, and 34 were identified as having cystic fibrosis after clinical examination and sweat testing. One hundred and two false positives had a normal sweat test and no other indication to suggest a diagnosis of cystic fibrosis, although two raised trypsinogen concentrations had been measured. Fourteen children subsequently were diagnosed as having cystic fibrosis, although they did not have raised concentrations of trypsinogen on screening. Of these false negatives, three infants born in the first year of screening had results between the 95th and 98th centile. In two other babies an initial raised trypsinogen result was followed by a low concentration on repeat testing, and in the rest of those with a false negative result at no time was the concentration of trypsinogen raised.

A total of 12 infants presented with meconium ileus. Two of the 12 infants had raised trypsinogen concentrations and would have been identified by the screening programme; the remainder all had low trypsinogen concentrations. It is our policy, however, to carry out a sweat test on all infants with meconium ileus thus identifying those with cystic fibrosis.

The range of immunoreactive trypsinogen concentrations for 34 true positive and 102 false positive results are shown in fig 2 . The trypsinogen concentrations in both of these groups range from $80->200$ $\mu \mathrm{g} / \mathrm{l}$. The median values for the true positive groups are $200 \mu \mathrm{g} / \mathrm{l}$ for the initial screening result, and 146 $\mu \mathrm{g} / \mathrm{l}$ for the repeat test; in the false positive group the median values for the two tests are $110 \mu \mathrm{g} / \mathrm{l}$ and $122 \mu \mathrm{g} / \mathrm{l}$ respectively. On the basis of trypsinogen testing there was no way to separate the false positive results from those that were later shown to be associated with cystic fibrosis on the basis of sweat testing.

\section{SWEAT TEST}

A sweat test was carried out on all infants with two raised immunoreactive trypsinogen results. The mean sweat sodium concentration at diagnosis for infants with cystic fibrosis was $92 \mathrm{mmol} / \mathrm{l}$, with a range of values from 70 to $135 \mathrm{mmol} / \mathrm{l}$. The corresponding values for the false positive group were $18 \mathrm{mmol} / \mathrm{l}$ and $9-33 \mathrm{mmol} / \mathrm{l}$. In 27 infants with cystic fibrosis, who also had a sweat chloride measurement, 25 had a sweat chloride concentration in excess of the sweat sodium concentration, and in 24 of these 27 infants the sum of the sodium and chloride concentrations was greater than $140 \mathrm{mmol} / \mathrm{l}$.

Seven infants with high trypsinogen values, who 


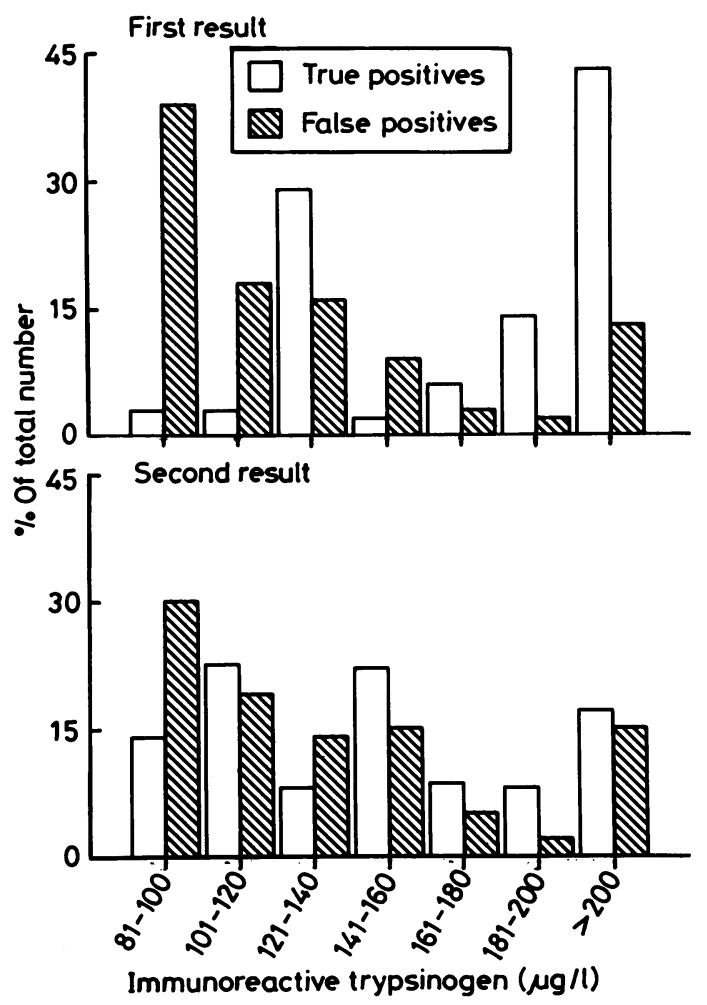

Fig 2 Distribution of blood immunoreactive trypsinogen results in 136 infants who had high (>95th centile) concentrations on two occasions. Thirty four infants were subsequently shown to have cystic fibrosis (true positives).

were shown to have cystic fibrosis, had a sweat sodium concentration in the range $40-70 \mathrm{mmol} / \mathrm{l}$ on their initial sweat test, and a further infant had an initial sweat sodium concentration of $15 \mathrm{mmol} / \mathrm{l}$. In each of these children the sweat test was repeated either because of strong clinical indications of cystic fibrosis, or because there was a family history of cystic fibrosis, and eventually a diagnosis of cystic fibrosis was supported by three sweat sodium estimations of $>70 \mathrm{mmol} / \mathrm{l}$.

When an infant was diagnosed as suffering from cystic fibrosis, all other siblings were sweat tested. In 1984, after diagnosis of cystic fibrosis in a 6 week old girl after positive screening results, three older children of the family were sweat tested. Two of these had positive sweat tests and were diagnosed as having cystic fibrosis. Their ages were 3 years and 5 years. The older child had been treated for rectal prolapse at the age of 2 years, but the possible diagnosis of cystic fibrosis had not been considered.
CLINICAL ASSESSMENT

Most of the infants shown to have cystic fibrosis as a result of the screening programme already had signs or symptoms, or both, of cystic fibrosis as shown in table 1 . In the four year screening period seven infants $(20 \%$ of those subsequently shown to have cystic fibrosis) were totally asymptomatic at the time of diagnosis. Three children had severe chest infections and the diagnosis of cystic fibrosis had been suspected before the immunoreactive trypsinogen results were known. In 24 children, however, the diagnosis had not been suspected until the screening results became available. When examined by the paediatricians involved in this study, 12 were found to have a history of mild chest infection, 13 to have persistent diarrhoea, and an additional five had no obvious symptoms suggestive of cystic fibrosis, although they were underweight for their age.

Table 2 shows that of those children with cystic fibrosis and low immunoreactive trypsinogen values on screening, only three in the four year period were asymptomatic; these children were investigated after the diagnosis of cystic fibrosis in siblings. The remainder had pronounced symptoms, the most important feature being failure to thrive, attributed in four cases to repeated pulmonary infections and to persistent diarrhoea in the remainder.

EFFECT OF SCREENING ON THE AGE AT DIAGNOSIS Table 3 shows that the median age at which the

Table 1 No of infants with cystic fibrosis, identified by screening, and their symptoms at presentation

\begin{tabular}{lllll}
\hline Symptom & $1983 / 4$ & $1984 / 5$ & $1985 / 6$ & $1986 / 7$ \\
\hline Failure to & & & & \\
$\quad$ thrive & 5 & 4 & 5 & 4 \\
Diarrhoea & 2 & 3 & 5 & 3 \\
Chest infection & 6 & 3 & 3 & 3 \\
Asymptomatic & 2 & 1 & 2 & 2 \\
\hline Total No/year & 9 & 7 & 9 & 9 \\
\hline
\end{tabular}

Table 2 No of infants with cystic fibrosis, missed on screening, and their symptoms at presentation

\begin{tabular}{lllll}
\hline Symptom & $1983 / 4$ & $1984 / 5$ & $1985 / 6$ & $1986 / 7$ \\
\hline $\begin{array}{llll}\text { Failure to } \\
\text { thrive }\end{array}$ & 2 & 5 & 2 & 0 \\
$\begin{array}{l}\text { Diarrhoea } \\
\text { Chest infection }\end{array}$ & 2 & 1 & 1 & 0 \\
Asymptomatic & 1 & 4 & 3 & 0 \\
\hline Total No/year & 2 & 0 & 1 & 0 \\
\hline
\end{tabular}

*None identified so far. 
Table 3 Age at diagnosis before and after screening

\begin{tabular}{|c|c|c|c|c|}
\hline $\begin{array}{l}\text { Year of } \\
\text { birth }\end{array}$ & $\begin{array}{l}\text { Total No } \\
\text { diagnosed }\end{array}$ & $\begin{array}{l}\text { No missed on } \\
\text { screening }\end{array}$ & $\begin{array}{l}\text { No with } \\
\text { meconium ileus }\end{array}$ & $\begin{array}{l}\text { Median age at } \\
\text { diagnosis (range) }\end{array}$ \\
\hline \multicolumn{5}{|c|}{ Not screened } \\
\hline 1980/1 & 12 & - & 2 & $\begin{array}{l}6 \cdot 8 \text { months } \\
\text { (6 weeks- } 7 \text { years) }\end{array}$ \\
\hline $1981 / 2$ & 13 & - & 2 & $\begin{array}{l}4.5 \text { months } \\
(4 \text { weeks }-4 \text { years })\end{array}$ \\
\hline $1982 / 3$ & 14 & - & 1 & $\begin{array}{l}9 \cdot 5 \text { months } \\
\text { ( } 4 \text { weeks- } 4.5 \text { years) }\end{array}$ \\
\hline \multicolumn{5}{|c|}{ Screened } \\
\hline $1983 / 4$ & 15 & 4 & 2 & $\begin{array}{l}6 \text { weeks } \\
\text { (4 weeks- } 2.5 \text { years })\end{array}$ \\
\hline $1984 / 5$ & 14 & 6 & 1 & $\begin{array}{l}6 \text { weeks } \\
\text { ( } 4 \text { weeks-23 months) }\end{array}$ \\
\hline $1985 / 6$ & 15 & 4 & 2 & $\begin{array}{l}6 \text { weeks } \\
\text { (4 weeks-14 months) }\end{array}$ \\
\hline 1986/7 & 16 & $0^{*}$ & 7 & $\begin{array}{l}4 \text { weeks } \\
\text { (4 weeks-8 weeks) }\end{array}$ \\
\hline
\end{tabular}

${ }^{*}$ None identified so far.

diagnosis of cystic fibrosis was made, since screening was commenced in August 1983, was six weeks, with a median age for infants born since August 1986 of 4 weeks; this was due to the large number who had meconium ileus in that year. Fourteen infants not identified by screening were diagnosed at a later date, the oldest being 2.5 years. In the three years before screening, the median ages for diagnosis of cystic fibrosis were 6.8 months, 4.5 months, and 9.5 months, and of children born in those years, the oldest age at which a diagnosis of cystic fibrosis was made was 7 years.

DIAGNOSTIC VALUE OF THE SCREENING TEST

On the basis of the screening results the sensitivity of the test was calculated as $60 \%$, the specificity $99.9 \%$, the predictive value of a positive result $34 \%$, and the predictive value of a negative result $99.9 \%$. The sensitivity of the test was improved to $73 \%$ if this figure was calculated having excluded negative results in infants born with meconium ileus. The known incidence of cystic fibrosis in Northern Ireland during this four year period was 1/1807.

\section{Discussion}

All infants born in Northern Ireland during the past four years have had immunoreactive trypsinogen concentrations measured on dried blood spot specimens. These samples were taken at the same time as those used in the screening procedure for phenylketonuria and congenital hypothyroidism. As a result of screening there has been a significant reduction in the age at which the diagnosis of cystic fibrosis is made. Furthermore, $20 \%$ of infants were judged to be totally asymptomatic at the time of diagnosis, and a further $17 \%$ had mild to moderate generalised symptoms not thought to be pathognomonic of cystic fibrosis. At the time of diagnosis these children were about 6 weeks of age, and most did develop specific symptoms at a later stage.

The region of Northern Ireland is a small one, with an annual birth rate of about 28000 , and there is not a great deal of population movement in and out of the region. There is one single large referral unit in Belfast for patients with cystic fibrosis. On account of these factors very few patients are lost to follow up, and this may contribute to the fact that in this paper we describe a higher incidence of false negative results than have been indicated in previous reports. Three infants who were false negatives, but with results close to our cut off value in the first year of screening, would have been detected if the lower cut off value had applied throughout the time of screening. Two further false negative results were caused by one high followed by a low trypsinogen concentration, and this may have been because of incorrect timing of the second specimens, as initially raised trypsinogen concentrations in cystic fibrosis are known to fall to within the normal range at varying rates in different infants. ${ }^{3}$ In the remaining nine false negatives the results of screening were well within the normal limits, and no explanation could be put forward to suggest why the results were low in infants with cystic fibrosis. Of 12 infants born with meconium ileus, 10 had low results on screening, 
a finding which has been reported in a number of studies. ${ }^{56}$ As children born with meconium ileus should be investigated for cystic fibrosis their low results on screening should not cause a serious diagnostic problem, although it is important to emphasise the relationship between meconium ileus and low concentrations of immunoreactive trypsinogen.

The number of repeat specimens requested during this period of screening was very high. A second specimen is obtained on all infants with results greater than the 95th centile for the assay; other centres quote much lower numbers of second specimens. ${ }^{36}$ In addition, the false positive rate for the screening assay was very high, with a false positive being defined as those having two raised immunoreactive trypsinogen results, but a normal sweat test, and no clinical signs of cystic fibrosis. Although the median trypsinogen result for the second specimen showed a tendency to be lower for false positives compared with those infants who did have cystic fibrosis, there was no clear cut difference between the groups.

It is widely recognised that definitive sweat test results are not always easy to obtain. ${ }^{78}$ In this context it is often recommended that sweat tests should be carried out by fully trained personnel, using a well defined protocol ${ }^{4}$; in the sweat tests carried out as a result of our screening programme we have found these factors to be important. A recent report describes sweat tests in young infants with an ultimate diagnosis of cystic fibrosis, but with sweat sodium concentrations below $60 \mathrm{mmol} / \mathrm{l}$ at the time of the first sweat test. ${ }^{9}$ Eight children with raised trypsinogen concentrations in our screening programme had a sweat sodium that was not sufficiently high at 6 weeks of age to confirm cystic fibrosis. In seven of these children equivucal sweat test results were obtained on a number of occasions, but in one child with an initial sweat sodium concentration of $15 \mathrm{mmol} / \mathrm{l}$ no further sweat tests were carried out until the child was 2.5 years old. Each of these children has subsequently been identified as having cystic fibrosis on the basis of clinical data, family history, trypsinogen results, and eventually all have been shown to have abnormal sweat electrolytes on three separate occasions.

These results serve to indicate that especially in young children the sweat test cannot always be considered to be reliable, and a diagnosis of cystic fibrosis should be considered if the clinical findings point to this, even in the presence of equivocal or normal sweat electrolyte concentrations. In addition, we have found it necessary to establish appropriate reference ranges for sweat sodium and chloride concentrations in the population of young infants requiring sweat tests as a result of positive trypsinogen screening values.

From the description of symptoms seen in those children identified by screening as having cystic fibrosis, it can be appreciated that $20 \%$ were truly asymptomatic when diagnosed at this early age. An interesting feature was the number of infants presenting at 6 weeks with failure to thrive or inadequate weight gain. In most cases this was due to the infant having diarrhoea. In some cases the parents, particularly those of first born children, did not realise that the child was having frequent bowel movements; they accepted their child as being normal. Health professionals concerned with advising parents should be aware of the possibility of cystic fibrosis in an infant with mild diarrhoea or inadequate weight gain. In several cases the parents had been advised that their child was allergic to milk products, although they were eventually shown to have cystic fibrosis.

From the results in table 3 it can be seen that the median age at diagnosis for the screened population is less than that for children born in the three years before screening. It is possible that additional false negative cases will be identified in the future. It should be noted, however, that in the last seven years the number of children in Northern Ireland shown to have cystic fibrosis has remained reasonably constant, with 13-16 children being diagnosed each year. In addition the overall known incidence of cystic fibrosis in Northern Ireland during the last four years is $1 / 1807$, which is a high incidence, making it unlikely that there are many more unidentified infants with cystic fibrosis born during this period of time.

In conclusion, this screening programme has resulted in a lowering in the median age at which the diagnosis of cystic fibrosis is made and a considerable reduction in the anxiety of parents with an undiagnosed sick child. It is also possible to offer genetic counselling to these parents. It must be recognised that in our hands immunoreactive trypsinogen has not proved to be an ideal screening test for cystic fibrosis. The clinicians involved in the study, however, feel that because of the earlier age at diagnosis in a large number of infants with cystic fibrosis the screen should continue for a further period of time. It seems likely that other tests that closely reflect the underlying genetic or metabolic abnormalities will soon become available.

We would like to thank Professor E Trimble of the department of clinical biochemistry, Royal Victoria Hospital, Belfast for her advice and encouragement. We are also grateful to the members of staff of the department of clinical biochemistry, Royal Victoria Hospital, and of the department of biochemistry, Royal Belfast Hospital for Sick Children, who carried out the analyses, the 
community staff who provided the specimens, and Miss Dawn Fenning for preparation of the manuscript.

\section{References}

1 Crossley JR, Elliott RB, Smith PA. Dried blood spot screening for cystic fibrosis in the newborn. Lancet 1979;i:472-4.

2 Crossley JR, Smith PA, Edgar BW, Gluckman PD, Elliott RB. Neonatal screening for cystic fibrosis, using immunoreactive trypsin assay in dried blood spots. Clin Chim Acta 1981;113: 111-21.

${ }^{3}$ Heeley AF, Heeley ME, King DN, Kuzemko JA, Walsh MP. Screening for cystic fibrosis by dried blood spot trypsin assay. Arch Dis Child 1982;57:18-21.

${ }^{4}$ Gibson LE, Cooke RE. Test for concentration of electrolytes in sweat in cystic fibrosis of pancreas utilizing pilocarpine by iontophoresis. Pediatrics 1959;23:545-9.

${ }^{5}$ Duhamel JF, Travert G, Delmas P, Brouard J, Venezia R.
Special features of the time related evolution in IRT blood levels, in six out of seven newborns with cystic fibrosis complicated by meconium ileus. In: Lawson D, ed. Cystic fibrosis horizons. Chichester: J Wiley, 1984:208.

6 Wilcken B, Brown AR, Urwin R, Brown DA. Cystic fibrosis screening by dried blood spot trypsin assay: results in 75000 newborn infants. J Pediatr 1983;102:383-7.

${ }^{7}$ Shwachman H, Mahmoodian A, Neff RK. The sweat test: sodium and chloride values. $J$ Pediatr 1981;98:576-8.

${ }^{8}$ Green A, Dodds P, Pennock C. A study of sweat sodium and chloride: criteria for the diagnosis of cystic fibrosis. Ann Clin Biochem 1985;22:171-4.

y O'Halloran M, Brown J, Wilcken B. Diagnosis of cystic fibrosis. Lancet 1987;ii:1156.

Correspondence to Miss G Roberts, Biochemistry Laboratory, Royal Victoria Hospital, Belfast BT12 6BA.

Accepted 6 June 1988 